\section{Meet your microbiome}

\author{
John Launer
}

Last year I had the privilege of meeting Elling Ulvestad, a Norwegian microbiologist who is also a philosopher. $\mathrm{He}$ is a man of enormous warmth and energy, as well as having inexhaustible enthusiasm for his subject. He can soon convince anybody that the world is in great need of a philosophy that is properly informed by microbiology, and vice versa. Here are the kinds of facts that Professor Ulvestad has on the tip of his tongue. We carry 10 times as many bacterial cells around on our bodies as we do of our own cells (the disproportion is because microbes are very much smaller than mammalian cells). If you also count the bacteriophages that inhabit bacteria, the ratio of microorganisms to human cells on each of us is probably more like $1000: 1$. Although we commonly regard bacteria as enemies, only around 100 species regularly infect human beings, while literally millions of others either ignore us or co-operate with us in ways that ensure our survival. We are, in other words, not isolated individuals but walking ecologies. Our lumbering, multicellular bodies act as unwitting landlords to a vast community of far more resilient lodgers who could happily move to alternative accommodation in someone else's gut or skin-and quite often do.

Ulvestad's view of human-microbial interaction-and his publications on the subject-go far beyond these numerical facts. He points out that micro-organisms have been the 'chief molecular innovators' of the biosphere. ${ }^{1}$ Evolutionary history has been built on their ability to project life to greater degrees of complexity. Micro-organisms are, quite literally, our ancestors, and they have incorporated themselves within our own genome. Forty-five per cent of the human genome consists of transposons-DNA sequences that can copy and move within chromosomes-of which around 8\% are retrovirus-like. The DNA that regulates the interaction between the cell and its mitochondria is derived from bacteria. Mitochondria are of course themselves the descendants of formerly free-living bacteria. They have lost their ability to reproduce independently, but have made

Correspondence to Dr John Launer, London Department of Postgraduate Medical Education, London Deanery, Stewart House, London WC1B 5DN, UK; jlauner@londondeanery.ac.uk up for this by being shielded from immune destruction.

The development of our intestines, immune systems and even our brains is dependent on our bacterial cohabitants. Experimentally, mice raised with intestines free of germs display different behaviour from those which are allowed to acquire commensal bacteria. If the sterile mice are recolonised with bacteria while still in infancy, their behaviour becomes normal. If they are already adults, it does not. As Ulvestad argues 'Development impinges on evolution because it ties the organism up in a system of references to other living and non-living entities in between fertilisation and death'. Immune competence, he points out, should be understood as 'a relational property that transcends the boundary of the organism'. Thus, it should not surprise us if eradicating an obvious intestinal pathogen like Helicobacter pylori from the ecology may result in a backlash with a possibly increased incidence of asthma, diabetes and metabolic syndrome. ${ }^{3}$

\section{SOCIAL LEARNING}

Humans are sometimes held up as the ultimate example of the ability to transfer information from one generation to the next, through the use of language and culture. However, bacteria can be regarded as equally adept at social learning. ${ }^{4}$ They transfer genes with massive frequency, so that in some species only about $40 \%$ of the genome is common to all individuals. Ulvestad likens their uptake of ready-made genes from a mobile gene pool to the rapid uptake of new ideas by humans of information from the internet. This can be to the disadvantage of humans-for instance, in the way that Neisseria gonorrhoeae has developed resistance to all known drugs. It can also benefit us. One example is the way that Japanese people who regularly eat seaweed can digest the polysaccharide porphyran because the bacteria on seaweed can transfer the gene for the appropriate enzyme to human intestinal flora. Bacteria also indulge in what Ulvestad calls 'cross-talk': they release and sense diffusible molecules that allow them to respond collectively to the environment in a coordinated manner-for example, by manufacturing biofilms to defend against antibiotics. They often do so by 'quorum sensing', which enables them to know when their numbers are sufficient for such collaborative projects to be feasible.

One of Ulvestad's missions is to try to help everyone move away from the 'war' metaphor when talking about microorganisms. This pervasive metaphor in medicine arose in the nineteenth century, largely because most researchers were doctors, and they focused almost exclusively on pathogens. He reminds us that at least one of the great early immunologists-the Russian, Ilya Mechnikov-was more concerned with studying how competition and co-operation were finely balanced in biology. More than a century after Mechnikov, this perspective has become almost universal in evolutionary and biological studies. A modern evolutionary view does not see any organisms-from viruses to humans-as intrinsically good or bad, but applies scientific curiosity in order to establish how hosts and infectious agents negotiate relationships along a scale from lethal hostility to symbiotic harmony. Ulvestad writes: 'As scientists, we need to acknowledge the fact that we are only studying a brief interlude of biological time, which represents the current trade-offs reached by contemporary organisms subject to a number of evolutionary forces... These forces are still acting to diversify and complicate the biological processes, and the results of the trade-offs reached will be the challenges encountered by future scientists'.

\section{INFORMED VIEW}

If Ulvestad is right, the view that doctors and pharmacologists often have of themselves as heroic warriors has surely run its course. We need to start thinking about infectious diseases, and maybe all diseases, not in terms of the battlefield but with the mature, eco-systemic, biologically informed view that he sets out. A hopeful development in this respect in the Human Microbiome Project, which aims to characterise all the microbial communities on the human body, and to analyse their roles in human physiology and development. ${ }^{5}$ Many of our health-giving microorganisms have never been isolated or cultured, and it is only the sequencing of genes for ribosomal RNA that is now making identification possible. One outcome of this project has been to establish that that there is a remarkable diversity of organisms among healthy people, with each of us bearing an almost unique 'microbiome' alongside our unique genome. While some microbiomes may turn out to be associated with particular diseases or syndromes, others may confer protection. 
Every generation of doctors and scientists tends to regard itself as having reached a pinnacle of understanding. ${ }^{6}$ We incline rather easily to the belief that our overall paradigm for understanding the world has been perfected, and it is only the details that remain to be filled in. Ulvestad's view has the potential to shake this complacency for the next generation of medical researchers and clinicians. If the past 50 years have been the age of the genome, we may be about to enter the era of the microbiome, where we start to pay respect not only to ourselves, but also to the far more ancient, numerous, adaptable and largely collaborative micro-organisms on which our existence depends.

\section{Competing interests None.}

Provenance and peer review Commissioned: internally peer reviewed.

To cite Launer J. Postgrad Med J 2013;89:367-368.

Postgrad Med J 2013;89:367-368.

doi:10.1136/postgradmedj-2013-132066

\section{REFERENCES}

1 Ulvestad E. Co-operation and conflict in host-microbe relations. APMIS 2009;117:311-22.

2 Ulvestad E. Psychoneuroimmunology: the experiential dimension. Methods Mol Biol 2012:934:21-37.

3 Willyard C. A tough controversy to stomach. Nat Med 2009:15:836-9.

4 Ulvestad E. Defending life: the nature of host-parasite relations. Dordrecht: Springer, 2007.

5 Friedrich MJ. Genomes of microbes inhabiting the body offer clues to human health and disease. JAMA 2013;309:1447-9.

6 Kuhn T. The structure of scientific revolutions. Chicago: University of Chicago, 1962. 